\title{
RESENHA
}

PRADO JÚNIOR, Caio. História e Desenvolvimento: a contribuição da historiografia para a teoria e prática do desenvolvimento brasileiro1. 2. ed. São Paulo: Ed. Brasiliense, 1978

Brenda T. Cardoso de Castro - Doutoranda no Programa de Pós-Graduação em Sociologia e Antropologia - PPGSA/UFPA. Mestre em Ciência Política (PPGCP/ UFPA).E-mail: brendatcc@gmail.com

O desenvolvimento é um tema que muito determinou os caminhos das discussões e temáticas da Sociologia Brasileira, entretanto, o debate não se esgotou nas profícuas décadas de 1960, 1970 e 1980. A releitura contemporânea das dinâmicas históricas, econômicas e políticas dos processos de colonização também convidam a retornar a pensamentos de clássicos brasileiros a partir de novos contextos. Neste âmbito, propõe-se aqui uma revisitação à obra de Caio Prado Júnior sobre desenvolvimento e história do Brasil, colocando em destaque, além das contribuições do historiador, o pensamento e a representação da Região Amazônica inserida na ideia de desenvolvimento. Conclui-se que apesar do pensamento de ruptura proposto por Caio Prado Júnior nos anos 1960, sua visão no que concerne à Amazônia de certo modo ainda reproduzia e reforçava a lógica desenvolvimentista e de modernização, não de modo a invalidar seus pensamentos, mas demonstrando a necessidade de reconhecer os marcadores regionais históricos e a própria produção do conhecimento como necessário para a construção de uma sociologia brasileira mais próxima às idiossincrasias do país.

A questão do desenvolvimento é um tema que perpassa as Ciências Sociais desde a sua origem no contexto da modernidade e as ideias de progresso, marcando profundamente as diretrizes da disciplina que se expandiria da Europa para o restante do mundo a partir do século XIX.

Entretanto, ainda que seja recorrente a discussão sobre desenvolvimento nas Ciências Sociais, a sua origem é profunda na Economia, o que influenciou

Est artigo é resultado das discussões da disciplina Sociologia Brasileira, ministrada no mês de novembro de 2017 pela Profa. Dra. Edila Moura e o Prof. Dr. Renan Pinto no Programa de Pós-Graduação em Sociologia e Antropologia da UFPA (PPGSA/UFPA). 
o fato de muitas vezes as abordagens resumirem-se a parâmetros e índices econômicos na sua análise. Assim, quando a partir dos anos 1950 começam a ganhar reverberação estudos e publicações sobre o desenvolvimento e o caso dos países latino-americanos, como na criação da Cepal pela ONU e a difusão de várias teorias como a Teoria do Desenvolvimento, a Teoria da Dependência e a Teoria da Autonomia, são feitas contribuições de ruptura do pensamento sobre desenvolvimento como fenômeno apenas econômico.

Neste âmbito, pode-se inserir a publicação de Caio Prado Júnior de 1968 intitulada "História e desenvolvimento", em que o pensador critica as abordagens estritamente economicistas e propõe uma reconsideração do aspecto histórico para a compreensão do desenvolvimento no Brasil.

O presente texto pretende discorrer sobre a premissa principal trazida por Caio Prado Júnior e o seu impacto na discussão sobre desenvolvimento e, em seguida, realiza-se uma ponderação mais profunda sobre a análise regionalizada com enfoque no caso da Amazônia a partir da leitura.

Por fim, apontam-se possíveis continuidades com base no trabalho de Prado Júnior, seguindo provocações de contestações do caso amazônico e pensamentos de autores complementares, como dos estudos pós-coloniais.

\section{HISTÓRIA, DESENVOLVIMENTO E AMAZÔNIA}

Caio Prado Júnior (1907-1990) ocupa lugar de referência no pensamento brasileiro e influencia para além da História, também as Ciências Sociais. Nascido no início do século XX na capital de São Paulo, parte do centro político e econômico do país em uma família aristocrata, Prado Júnior teve uma trajetória diferente de outros pensadores brasileiros, não seguindo um caminho tão tradicional enquanto professor acadêmico, mas tendo muito impacto e contribuição nos seus estudos e publicações, facilitadas pelo fato de ser um dos fundadores da Editora Brasiliense em 1943.

Em 1928, obteve o bacharelado em Direito e atuou principalmente como livre-docente na área de Economia Política, referência importante para o contexto das suas contribuições críticas na obra sobre o viés econômico dado ao desenvolvimento.

Reler a obra de Caio Prado Júnior cinquenta anos depois da sua publicação é um convite a reconhecer tanto as contribuições no momento em que o livro foi escrito e o lugar que o autor e a discussão sobre desenvolvimento viria a ocupar na Sociologia brasileira, como também reconsiderar pontos que na época pouco ressoaram diante do ponto principal de ruptura que era proposto. 
Assim, nesta seção será apresentado o primeiro ponto acima: as contribuições e o significado de ruptura da obra "História e desenvolvimento" no contexto em que se dá a sua publicação. Em seguida, discutir-se-á um dos pontos que se convida a reanalisar na obra do autor: a sua visão e representação da Amazônia.

\subsection{CONTRIBUIÇÕES E RUPTURAS EM "HISTÓRIA E DESENVOLVIMENTO"}

Analisar um pensamento após cinquenta anos tem seus riscos, sendo o principal o anacronismo. Para realizar uma releitura crítica é preciso cautela no esforço de reconhecer as contribuições e o significado do texto em sua época e as condições em questão, o que muitas vezes após décadas, com o pensamento nele contido já difundido pode parecer para quem o lê posteriormente algo óbvio ou até mesmo pequeno. Entretanto, o outro risco é de não exercer a reflexão crítica da obra justamente por suas limitações históricas, a ponto de relativizar totalmente qualquer produção dada em outro tempo.

Isto posto, "História e desenvolvimento" traz como grande argumento a crítica a abordagens mais tradicionais de desenvolvimento, quase que restritamente ligadas à economia, o que, para ele, são insuficientes se não consideram também a história do contexto analisado, no caso, do Brasil:

O meu objetivo central, no presente trabalho, foi reivindicar para ela [a história], particularmente no caso brasileiro, o que de direito lhe cabe como fonte informativa e explicativa do processo de desenvolvimento do nosso país, chamando a atenção para a especificação de nossa formação (PRADO JÚNIOR, 1978, p. 7).

E é partindo desta premissa que Prado Júnior traça a história da formação do Brasil - a partir da colonização, ou seja, da chegada dos portugueses/europeus -, destacando a "função" primária atribuída ao território em questão, diferente de outras formas de colonização como dos EUA, o Brasil já tem na sua origem uma inserção como fonte de matéria-prima para atender a uma demanda externa. O que significa dizer que já se inicia na dinâmica do comércio internacional, ao contrário de outros Estados, que passam pela formação de uma identidade nacional, ou seja, a consolidação de um contexto cultural e político.

No Brasil, o processo é difuso: todas as estruturas (políticas, econômicas etc.) são criadas e pensadas de e para a necessidade da metrópole:

Não é a colonização que empreendeu e desenvolveu o aproveitamento da exploração canavieira, e sim o contrário: é essa exploração que deu origem à colonização e ao Brasil. [...] Não é a economia do açúcar que 
se conforma e adapta às necessidades de uma sociedade preexistente que nela procura a base econômica de sua subsistência. E sim, é esta sociedade que se origina, dispõe e organiza em função da finalidade precípua de produzir açúcar, e assim realizar um negócio. Negócio que tem, não como objetivo (pois o objetivo próprio de todo negócio é tão-somente o lucro mercantil), mas como o objeto o atendimento de necessidades e de um consumo estranhos ao país e à coletividade nele instalada (ibid., p. 37).

O exemplo dado sobre a cana-de-açúcar já havia sido também precedido pelo caso da exploração do pau-brasil e no âmbito da cana-de-açúcar a questão é crítica no sentindo também de uma transformação na cultura alimentar imposta pelas dinâmicas do mercado externo, enquanto a mandioca, base da alimentação em toda a extensão territorial, começa a perder espaço, no momento em que todos os recursos de terra e produção são voltados para a cana (além dos impactos ambientais da prática da monocultura).

Pode-se remontar a este contexto a desigualdade no sentido da fome e da insegurança alimentar para a população nativa deste contexto, assim como a prática da exploração forçada de mão-de-obra, primeiramente indígena e posteriormente africana, o que reforça o argumento de padrão de uma estrutura e formação da sociedade brasileira voltada tão somente para o mercado externo e a partir das necessidades e prioridades dos colonizadores, indiferente às demandas locais.

Em suma, apesar das transformações históricas que seguem os séculos no Brasil, Prado Júnior continua identificando a permanência da lógica da ideia de desenvolvimento no país servindo ao interesse do capital externo: nos outros ciclos econômicos que seguem após a cana-de-açúcar e o processo da Revolução Industrial na Europa, assim como os processos de modernização e construção de ferrovias e portos para a exportação da produção brasileira.

Apesar da independência formal de Portugal, percebe-se a continuação da concentração de poder e capital nas elites, dando seguimento na condição de desigualdade e dissonância de interesses elitistas da população em geral, desde o início marginalizada e desconsiderada como detentora do poder e do interesse do Estado.

Nesta ótica, pode-se compreender que até mesmo os avanços nos direitos civis, políticos e sociais acabam por girar em torno desta demanda externa de inserção no mercado internacional, marcada já no início da colonização e que com algumas roupagens novas durante os séculos acaba por se remodelar, mas reproduz a mesma relação de subordinação.

A crítica central a partir da construção do argumento de Prado Júnior é a ideia de uma limitação rumo a este dito desenvolvimento, já que a condição 
periférica do Brasil no sistema internacional é histórica e a condução da formação brasileira em relação às demandas externas fragiliza a possibilidade de uma economia e uma sociedade autônoma de fato.

E é neste sentido que a obra de Prado Júnior dá força a um processo de revisão dos parâmetros de desenvolvimento e do contexto tanto latinoamericano quanto brasileiro, que viriam a ficar conhecidas como as teorias do Desenvolvimento (PREBISCH, 1954), da Dependência (SANTOS, 2000) e da Autonomia (JAGUARIBE, 1979); sendo também uma grande influência para o pensamento de Celso Furtado em sua contundente crítica ao desenvolvimento.

Diante desta premissa, propõe-se um aprofundamento do pensamento de Prado Júnior em alguns pontos que se consideram aqui como pouco explorados por ele e que de certo modo reproduzem a própria lógica de desenvolvimento como fator universal e ocidental e a partir de autores complementares serão propostas a seguir revisões de abordagens especificamente sobre a questão amazônica no texto de Prado Júnior.

\subsection{A IDEIA DE AMAZÔNIA EM “HISTÓRIA E DESENVOLVIMENTO”}

No que se propõe a discussão de Prado Júnior - o argumento central da relevância de uma abordagem histórica para a análise do desenvolvimento no Brasil - e a construção das relações históricas e econômicas é bem sucedida, porém, talvez dado o contexto da produção acadêmica que levou à publicação como um caráter complementar de sua trajetória, aqui, aponta-se que a mesma apresenta limitações.

Ao analisar o processo de colonização do Brasil é preciso considerar as idiossincrasias regionais, os diferentes processos de ocupação e as consequências atuais. Falar de história e desenvolvimento no país é, também, falar dos processos que levarão às assimetrias e desigualdades regionais marcantes até hoje em dia.

A abordagem feita por Prado Júnior mantém um caráter de visão do Sudeste do país e ao tratar o desenvolvimento relega à Região Amazônica à periferia deste processo, reproduzindo, inclusive mitos e preconceitos sobre a mesma:

Além da resistência que ofereceu ao trabalho escravo, o índio se mostrou muito mau trabalhador, de pouca resistência física e de eficiência mínima. Nunca teria sido capaz de dar conta de uma tarefa colonizadora levada em grande escala. Está aí o exemplo da Amazônia, onde não chegou a ser substituído em escala apreciável por outro trabalhador; e onde, em grande parte por isso, a colonização estagnou até quase nossos dias (PRADO JÚNIOR, 1978, p. 42). 
Os elementos atribuídos no trecho acima pouco diferem da visão da época que atribuía certo "atraso" da Região Amazônica em relação às outras (especialmente do Sudeste) às populações indígenas (que existiam, na verdade, em todo território nacional).

Logo, atribuir à cultura dos povos nativos o "fracasso" da colonização na região reproduz uma visão ocidentecêntrica que hierarquiza as culturas ainda na base das dinâmicas econômicas (menos ou mais capitalistas). Ademais, uma visão também falaciosa, haja vista que a distribuição de populações indígenas por todo o território não foi impedimento para o genocídio e extermínio em regiões que a Metrópole atribuiu maior interesse como a costa brasileira e a região Sudeste.

Prado Júnior continua a sua consideração sobre os indígenas afirmando que:

O índio brasileiro, saindo de uma civilização muito primitiva, não se podia adaptar com a necessária rapidez ao sistema e aos padrões de uma cultura tão superior à sua como era aquela que lhe traziam os europeus. O Brasil, neste assunto, estava em situação bem diversa da do México e dos países andinos, onde a colonização encontrou populações de nível cultural elevado (id.).

O argumento é frágil, já que as assimetrias e desigualdades socioeconômicas presentes na Região Amazônica brasileira também se encontram em países andinos e no México atualmente, reforçando que não é a causa do dito atraso a cultura dos povos locais, mas sim o próprio processo de colonização levado a cabo pelos colonizadores europeus.

No caso da Amazônia, por exemplo, a região passou por muito tempo fora do enfoque da Metrópole, recebendo atenção principalmente em casos como da ocupação espanhola e de outros povos europeus como franceses e holandeses que aproveitando o vazio da presença portuguesa se instalaram na região.

A partir deste trecho, Prado Júnior segue analisando a história e o desenvolvimento do Brasil basicamente a partir da perspectiva do Centro-Sul e dos ciclos econômicos da região, principalmente da cultura cafeeira, descrevendo as mudanças econômicas e políticas no Sudeste, mas desconsiderando as consequências e a própria situação em regiões marginalizadas politicamente como a Amazônia. Brevemente cita-se o ciclo da borracha, mas tão pouco se destaca a real importância do mesmo e muito menos se localiza a sua ocorrência, ao contrário da atenção dada às dinâmicas que se dão em São Paulo que são comentadas em seus pormenores.

A seguir, propõem-se revisitações críticas a partir da abordagem sobre a Amazônia feita por Prado Júnior ao aproximarmos suas discussões de vertentes teóricas contemporâneas como os estudos pós-coloniais. 


\section{CONTINUAÇÕES PARA "HISTÓRIA E DESENVOLVIMENTO” A PARTIR DA AMAZÔNIA}

Como fora abordado anteriormente, a discussão sobre desenvolvimento na Sociologia Brasileira não apenas não é um assunto recente, como é uma das principais marcas da formação da disciplina no país no século passado. No caso da Amazônia, o tema desenvolvimento também é recorrente e raramente se produz sobre a região sem que o tema esteja em voga.

Entretanto, não significa dizer que a discussão já tenha sido exaurida ou até mesmo, que não necessite ser reconstruída a partir de novas visões e novos pilares, considerando a origem das Ciências Sociais enquanto área moldada por pensadores europeus e que traduzidos e importados levaram à reprodução interna de parâmetros e epistemologias díspares das múltiplas realidades da América Latina.

A partir dos dois apontamentos realizados na seção anterior, sendo o primeiro a contribuição da argumentação de Prado Júnior no âmbito de compreender o desenvolvimento considerando a história e, o segundo, o lugar (ou a própria falta de ênfase) que a Amazônia ocupou na apresentação do seu argumento; considera-se que para atender de fato a proposta feita por Prado Júnior, ou seja, uma análise histórica do desenvolvimento no Brasil, é peça basilar a análise regionalizada.

Ao tomar como base contribuições de pensadores como Dussel (1977; 2005), Quijano (2000) e Escobar (2005) sobre o desenvolvimento é possível notar convergências ao pensamento de Prado Júnior, como quando este critica uma visão do desenvolvimento "como modelo universal e invariável” (ibid., p. 56), assim como a sua abordagem histórica que relaciona a situação de dependência e do "subdesenvolvimento" como parte do processo intrínseco à colonização, sendo a condição de dependência dificilmente superável considerando que toda a estruturação e a criação do país girou em torno de uma demanda do mercado externo e não das necessidades da própria população.

Considerando que a popularização acadêmica da crítica pós-colonial e de sua consolidação enquanto referência no pensamento social se dá apenas no século XXI, é importante reconhecer a contribuição de Prado Júnior em 1968 neste sentido.

Entretanto, estas leituras também convidam a provocar questionamentos sobre a produção dos conhecimentos e suas legitimidades. Assim, vemos a Região Amazônica como muitas vezes objeto do qual se fala de longe. 
Logo, revisitar a análise histórica de desenvolvimento numa perspectiva amazônica pode revelar muito mais que apenas uma região "atrasada" ou que foi relegada à margem do poder por conta da resistência de culturas "primitivas". Ao contrário, analisar este viés nos possibilita contestar o projeto universalista e homogêneo pautado no modelo ocidental de modernização e progresso.

Analisar as desigualdades do Brasil, mais do que as regiões que atualmente mais se aproximam do modelo de desenvolvimento europeu, serve mais como fonte de contestação da validade e viabilidade de uma ideia de desenvolvimento que de reafirmação de uma hierarquia cultural.

Isto posto, as tentativas forçadas e mal planejadas de imposição deste desenvolvimento de fora para dentro, de modo irregular, de costas para a própria população enquanto se mirava o sistema internacional e os lucros que dele viriam a uma pequena parcela elitista, contribuíram para a desestruturação das formas de vida - e de desenvolvimento - que existiam desde antes da colonização.

Séculos de colonização espacial, política e mental desembocam atualmente na Amazônia enquanto região de conflitos socioambientais intensos entre diversos povos pela utilização do território, por diferentes formas de compreender a relação com a natureza e que, muitas vezes, são dissonantes de um modelo de desenvolvimento enquanto modernização, no sentido que uma vida melhor muitas vezes tem se mostrado como cada vez mais como algo distante de tudo aquilo atrelado ao progresso.

As políticas desenvolvimentistas são exemplos que se intensificaram no final do século passado e que nos últimos anos recaíram sobre a polêmica construção da Usina Hidrelétrica de Belo Monte no município de Altamira, assim como outras já em planejamento.

Nestes contextos, o discurso de um projeto nacional visando o desenvolvimento e a geração de energia para a melhoria da vida da população, pela geração de emprego e renda, modernização e infraestrutura é enfrentado por grande parte da população das áreas dos empreendimentos com descontentamento e discordância de uma visão nacional e as suas visões próprias do que consideram uma vida melhor.

Enquanto numa lógica nacional homogênea e reprodutora de colonialidade se vê a região como atrasada por fatores ocidentais de avaliação como densidade demográfica e urbanização, muitas visões locais defendem seus modos de vida como ideais para si e vêem as políticas nacionais como violadoras de seus direitos.

Por fim, tem-se que mais do que uma relação de dependência historicamente construída e dificilmente superável para o Brasil pelo processo de colonização onde toda sua formação buscava (e ainda busca) atender a 
demandas externas, olhando-se para dentro existem reproduções desta relação a âmbitos regionais, como proposto por Pablo González Casanova (2015) na ideia de colonialismo interno.

\section{CONSIDERAÇÕES FINAIS}

Neste breve trabalho visou-se a apresentação da relevante contribuição de Caio Prado Júnior e seu livro "História e desenvolvimento" de 1968 para a Sociologia Brasileira e, especialmente, a Sociologia do Desenvolvimento, marca da disciplina no país.

A partir da exposição dos argumentos centrais formados por Prado Júnior traçou-se a importância da sua ideia central - uma análise do desenvolvimento não apenas no viés econômico, mas também histórico - o que em sua proposta leva à afirmação de uma condição brasileira de dependência enquanto periferia do sistema internacional que remete ao próprio processo de colonização.

Entretanto, a partir de algumas passagens em que o autor descreve a Amazônia brevemente nesta dinâmica, nota-se a reprodução de mitos e preconceitos sobre a região, o que se buscou contestar a partir da própria máxima de Prado Júnior e fazendo uso também de visões complementares dos estudos pós-coloniais.

Em suma, o exercício aqui proposto visou apontar a possibilidade de revisitar referências clássicas da Sociologia Brasileira e atualizar discussões muitas vezes de difícil visualização à época de suas publicações pelas próprias dinâmicas da produção de conhecimento normalmente eurocêntrica e que marcaram muitos dos precursores da Sociologia no Brasil, sendo a Amazônia apenas um exemplo para contestação de visões universais e homogêneas sobre os processos históricos e econômicos no país.

\section{REFERÊNCIAS}

DUSSEL, Enrique. Europa, modernidade e eurocentrismo. In: LANDER, Edgardo (Org.). A colonialidade do saber: eurocentrismo e ciências sociais perspectivas latino-americanas. Buenos Aires: CLACSO, 2005. p. 25-34.

Filosofia da Libertação na América Latina. Trad. Luiz João Gaio. 2. ed. São Paulo: Loyola/UNIMEP, 1977.

ESCOBAR, Arturo. Lugar da natureza e a natureza do lugar: globalização ou pós-desenvolvimento? In: LANDER, Edgardo (Org). A colonialidade do saber: eurocentrismo e ciências sociais - perspectivas latino-americanas. Buenos Aires: CLACSO, 2005. p. 69- 86 
FURTADO, Celso. O mito do desenvolvimento econômico. Rio de Janeiro: Paz e Terra, 1974.

GONÇALVES, Carlos Walter Porto. Amazônia, Amazônias. 3. ed. São Paulo: Contexto, 2015.

GONZÁLEZ CASANOVA, Pablo. De la Sociología del poder a la sociología de la explotación: pensar América Latina en el siglo XXI. Antología y presentación de Marcos Roitman Rosenmann. Bogotá: CLACSO, 2015.

JAGUARIBE, Helio. Autonomia periférica y hegemonia céntrica. Revista Estudios Internacionales, Santiago (Chile), v. 12, n. 46, p. 91-130, 1979.

PRADO JÚNIOR, Caio. História e desenvolvimento: a contribuição da historiografia para a teoria e prática do desenvolvimento brasileiro. 2. ed. São Paulo: Brasiliense, 1978.

PREBISCH, Raúl. La cooperacion internacional en la política de desarrollo latinoamericana. New York: Naciones Unidas, 1954.

QUIJANO, Aníbal. El fantasma del desarrollo en América Latina. Revista Venezolana de Economía Y Ciencias Sociales, Caracas, n. 2, p. 38-55, 2000. Disponível em: <http://www.cesla.uw.edu.pl/cesla/images/stories/ wydawnictwo/czasopisma/Revista/Revista_1_quijano.pdf $>$. Acesso em: 17 nov. 2017

SANTOS, Theotônio dos. A teoria da dependência: balanço e perspectivas. Rio de Janeiro: Civilização Brasileira, 2000. 